\title{
Aging, Immigration \& Carework: A Literary Approach to Teaching Gerontology
}

\author{
Pamela Pitman Brown (Corresponding author) \\ College of Arts \& Sciences, Albany State University \\ 504 College Drive, Georgia 31705 , United States \\ Tel: 1-229-500-2165 E-mail: pamela.brown@asurams.edu \\ Kelly Niles-Yokum \\ Department of Health \& Public Management, University of LaVerne \\ E-mail: kniles-yokum@laverne.edu
}

\begin{abstract}
This paper describes the use of a novel from the 1980s, Kate Quinton's Days which documents an Irish immigrant's challenges related to health, finances, housing, and the complex navigation of a fragmented health care system and social services, as a pedagogical tool in the classroom. The objectives were to bring to light to the topic of aging in the context of issues related to the experience of care work, immigration, and long-term care in later life. The authors describe the integration of a variety of pedagogical tools and the professor's guided learning process a way to assist in informing students' on the challenges that older persons and their care partners face as they attempt to navigate the landscape of care and identity. Reflections from the undergraduate gerontology students are highlighted, including how students were able to connect with the narrative of the protagonist, Kate Quinton, through her journey.
\end{abstract}

Keywords: immigration, carework, aging, learning through literature

DOI: $10.7176 / \mathrm{JLLL} / 65-06$

Publication date: February $29^{\text {th }} 2020$

\section{Introduction}

Immigration in the United States has increased over the past one hundred years, with a shift from European immigrants to those from Mexico, China, and India. According to a recent report by the Center for an Urban Future (Hamaji \& González-Rivera, 2016), nearly half (47\%) of all workers in New York City are immigrants, with 76 percent of the medical aides in the city also being immigrants. Additionally, the report notes that 79 percent of Brooklyn's home health aides are foreign-born. The report also states that two of the occupations with the largest growth in immigrant workers since 2000 are personal care aides (279 percent increase) and other healthcare practitioners and technicians (160 percent increase). Many of these immigrants are limited English proficient (LEP), meaning that irrespective of their education or training in their home country they are more concentrated in low wage occupations, particularly home health aides (Hamaji \& González-Rivera, 2016, p. 7).

There are over 430,000 immigrants aged 65 or older currently living in New York City. This highlights the fact that not all immigrants are young people searching for jobs or coming to the United States for an education. Many immigrants who moved to the United States in the 1980s and 1990s are now older, or may have moved here as middle-aged or older adults with their children. These immigrants may face language and cultural barriers, which, coupled with other socioeconomic factors, may contribute to challenges in navigating aging services that are available to them.

It's not just older adults who face challenges related to services and supports. Many students, particularly those who themselves are members of minority groups or underserved populations, may have difficulty accessing and or understanding information related to services and programs available to them. Integrating how immigrants face discrimination in similar situations presents challenges, which some instructors may decide is not relevant to their curriculum or not appropriate for the classroom. Seeing this as an opportunity to connect students to gerontological issues may instead, present educators with timely and relevant curriculum that can actually connect students to aging issues. As gerontologists, we argue that we have a duty to address these issues as we 
prepare an educated and culturally aware workforce. Thus using a novel documenting an immigrant's aging issues may put a name and a face to these topics and allow students to apply them to their own lives.

\section{Immigration, Aging, and Carework}

According to a 2018 report from the Institute for Women's Policy Research (Harmann, et al.), the United States has seen a substantial increase in naturalized and foreign born non-citizens in the area of care work between 2005 and 2015. Care work is defined differently according to setting and population, but most direct care is considered "reproductive labor" or hands-on tasks that are done such as bathing, toileting, house cleaning, etc. According to the International Labour Organization (2007), carework is defined as, "Work of looking after the physical, psychological, emotional and developmental needs of one or more other people." Naturalized citizens in the direct care workforce grew by 70 percent, with foreign born non-citizens employed in direct care work grew by 20 percent, with home-based adult care increases of 140 percent and 80 percent respectively. The report notes that the sharpest increase was in non-white foreign born citizens in adult care with 115 percent (p. vii). Additionally, this report highlights that adult care employment is projected to grow by 25 percent from 2014 to 2024, adding an additional 1.6 million jobs in elder care (Harmann, et al., \& Suh, 2018, p. 4; Bureau of Labor Statistics, 2015; Rolen, 2017).

Miller (2017), notes that immigration is needed in the United States in four key areas: Social Security, caregiving, healthcare, and housing. Miller states that the healthcare professions and direct care work in particular, are entering a crisis-level shortage of workers. This becomes even more relevant to the issues at hand related to immigration, care work, and later life, when we consider that 18 percent of certified nursing assistants, and 27 percent of home care aides are immigrants.

As Folbre (2012) notes, the primary responsibility of caring for older adults, specifically the "frail elderly," have traditionally been tasks assigned to women, with immigrant women and low-income African Americans represented more substantially in care work (p. xi). This concept is supported in other literature as well (Duffy 2005; Howes 2002) and as seen as the main theme in the novel, Kate Quinton's Days. It is also important to note that care work is divided into three categories: interactive care activities, support care activities, and supervisory care or "on-call" responsibilities, with all three of these categories being paid or unpaid care work (Folbre \& Wright, 2012, p. 23). Support care activities is also known as "reproductive labor".

In the novel Kate Quinton's Days, Sheehan focuses more on "non nurturant care" work (Duffy, 2011, p. 19) or "reproductive labor", which Folbre and Wright note as housework, meal preparation, and other tasks that "influence the quality of interactive care" (2012, p. 24). DeVault (1991) and Romero (1992) also discuss reproductive work as domestic service, such as cleaning, cooking, and other non nurturant care. An interesting intersection within Sheehan's text (1984) is that Kate came to the United States as an Irish immigrant from Scotland, and was a domestic worker prior to marriage and children (p. 96). During the time that Kate immigrated to the United States (1921), there were two options for poor immigrants, factory work or housework, and Kate chose housework (Sheehan, 1984, p. 96). This revelation further illustrates how immigrants provide and have provided care work in the United States for decades.

We also learn, through the telling of the story of Kate, that the family used chain-migration, where her father (Robert Donoghue) and the three oldest children (Kate, Sheila, and Anne) paid for their mother and the four youngest children's passage (p. 97). We learn that Kate's mother, Delia, sold off most of the belongings and left Scotland for Wilkes-Barre, Pennsylvania. All of these intimate details allow students to focus on how immigration has operated within the United States for many years, as well as the impact of this experience, including how this may affect later life.

\section{Simulations and Experiential Learning in the classroom}

Simulation activities are used frequently within sociology, gerontology and geriatric education. In fact, simulation and other non-traditional educational experiences are now normative in nursing, social work, gerontology, psychology, sociology, and other fields, with some of the earliest articles on simulation in gerontology and geriatric education being from the mid to late 1970s (Kauffman \& Luby, 1974; Sleet \& Corbin, 1979). As Small, Grabinski, and Bowman (2008) note, games/simulations not only bring reality into the classroom by creating real-world challenges and setting, but can also increase empathy and influence attitudes. King (1984) notes that games have more impact than conventional classroom teaching, while others note that games or role-playing are non-threatening (Chaisson, 1980), stating that games "counteract the normal resistance of fear and self-defense which often makes role playing difficult to initiate" (p. 590). 
Benjamin (1987) used simulation activities with gerontology students to provide insights into two types of aphasia communication disorders, Wernicke's and Broca's aphasia. Lavalliére and colleagues (2016) used an age suit to allow undergraduate engineering students the experience of aging, while grocery shopping, and promote awareness of insight into the structure of buildings, signage, and product placement, through an aging adult lens. As far as more difficult topics to broach, West (1983) used simulation exercises with community adults concerning "life situations" on plans of care, sexuality and aging, and residential sexual behaviors.

Karasik (2012), in discussing the current cohort of students, states that there are documented differences in learning styles and expectations of the students, and that they are more likely to be engaged in hands-onexperiences, teamwork, and technology (Johnson \& Romanello, 2005), with a low tolerance for long lectures and readings (Twenge, 2009). Baker and Brown (2015) also mention the concept of "hands-on minds-on task" in active and engaged learning, as well as working with real-world examples in a classroom.

\section{Pedagogical Approach}

3.1 Using literature in the classroom

As Deering (2018) discusses, using a novel or autobiography in a classroom can assist students in personal growth. This happens in a variety of ways but most importantly vis-a-vis, personal connection with the main characters and the story line. Additionally, Deering notes that using literature as a case study provides the student "with an immersive experience into a vivid case study that can be explored from the perspectives of a variety of characters with backgrounds both similar to and different from their own" (2018, p. 74; Flood \& Farkas, 2011; Gelman \& Mirabito, 2005).

Many students in gerontology will go on to become case workers, social workers, nursing supervisors, or nursing home directors, and thus the understanding of who immigrants are, where they are from, and how they became residents of the United States. Additionally, the immigrants' overall experience, is of importance, particularly when they will work with two elements of an immigrant population, one such as Kate Quinton, herself an older immigrant, and that of Kate's care workers who are young immigrants, coming to find work. This immersion into the novel allows for self-reflection, self-awareness, and also a sensitivity to the needs of the immigrants they will either have in their care, or in their supervisory capacity. Michaelson (2016) notes that when using literature rather than "cleansed" case studies, the student is given a more "complex and nuanced approach to understanding individuals and examining philosophical questions of how people should live and work" (Deering 2018, p. 75).

\subsection{Use of Kate Quinton's Days in the Classroom}

Brown \& Niles-Yokum (2016) detailed the use of Kate Quinton's Days (1984) as a collaborative venture between two educators with two different groups of students, and addressed curricula designed around the novel and related concepts. This was the impetus for this current exploration of the use of the novel in the classroom as a tool for introducing concepts related to aging issues in the context of carework and minority groups as well as autonomy and decision-making in acute and long-term care environments.

\subsection{Project Details}

In this particular project the students were instructed to read the text and then to locate a topic within the readings that was tied to aging issues. The students were then instructed to further explore the topics in depth, through additional readings and class discussions, and finally, relate it back to the text. Topics included legal, political and economics of aging, Social Security (including Widow's Benefits), Living Environments, Caregiver Turnover, and Family Dynamics. Additionally, students were allowed to choose from a variety of final product presentation options. Various presentation methods were offered as options due to the fact that students had access to and knowledge of a myriad of software programs. Students opted for a variety of presentation methods including Prezi, PowerPoint, YouTube, and a written final paper.

Below we will discuss the specific logistical approach to incorporating this work into the classroom. Additionally, the Academy for Gerontology in Higher Education (AGHE) competencies were integrated as a way to assess knowledge and identify outcomes. Students were tasked to complete a log of the characters within the novel, and to write on the characters' relationships to Kate, as well as their jobs/positions from a theoretical framework, such as continuity theory or symbolic interactionism. Students could also incorporate psychological, human developmental, or social theories along with gerontological theories. The students were encouraged to also keep track of the novel's timeline of events. 
In addition to the above information and a final presentation on topics such as policy, immigration, living environments, the students were required to write a reflection paper including what they gleaned from the narrative, how the book relates/related to their life/occupation or even to people they knew, and what gerontological/social work theories/concepts apply to Kate's life. They were also tasked as gerontology/social work students to discuss the family relationship dynamics and various terminologies that are used within both disciplines to describe some of the situations.

\section{Thematics of Student Reflections and Discussion}

\subsection{Life Course Perspective}

Using a life course perspective to consider how successfully or unsuccessfully Kate has aged seems the appropriate approach to interpreting the novel.

\subsection{Immigration Issues \& Economics}

Kate, like many other characters in this novel, is a first generation immigrant, because of her status and lack of formal "American" education she is struggling economically and socially. Kate is isolated and her background like many other immigrants is one of working low paying jobs that were paid with cash "under the table". She is living solely off of her husband's low Social Security benefits, by taking her widow benefits.

She moved to the United States to join her family to obtain the American Dream. The American dream is hard for immigrants to obtain due to cultural and language barriers, which often results in physically laborious low paying positions. The downfall of these positions, immigrants are forced to take, is that the Social Security that they receive is too low to support them in old age. This is why many immigrants like Kate suffer from poverty. Due to her immigrant status she was discriminated against within a system put in place to help her. Access to quality care and resources were frequently blocked or placed on hold by the social worker. The social worker slowed the delivery of service because she believed Kate and her daughter were not deserving of assistance.

In order to assist immigrants, such as Kate, we as gerontologist must advocate for older adult immigrants. This includes making changes in social policies and allocated resources.

4.3 Socio-Economic Status

The differences in Kate's social class and her daughter Barbara's social class caused conflict within the family. There was a power struggle within the family when it came to the support of Kate. Barbara believed Kate should simply be placed in a home and Claire wanted her mother to be able to remain in her home. Barbara seemed unwilling to support her mother or Claire in their decision to have Kate remain in the home with the use of in home healthcare. She tried to manipulate the situation by blaming them for their circumstances.

4.4 Healthcare Policy

Kate's story is similar to thousands of immigrants today. What I took from this novel was that America needs to rethink the policies on not only our healthcare system but on immigration and fare [sic] wages. This novel tells the story of not only Kate's struggle to survive as a first generation immigrant but of many others. The caregivers hired by Kate or social services in this novel were almost all first generation immigrants themselves struggling to catch a break and support their families. Even though the characters in this novel were allowed to legally work in the United States they still had little education and their access to adequate healthcare affected how they aged or will age.

Reading this novel showed me how a more universal healthcare system is needed. It also helps show that everyone working in the United States should also be able to pay into the social security and Medicare system regardless of immigration status, so EVERYONE can receive healthcare throughout their lives without the worry of deportation or the worry of how you might pay. Keeping residents healthy while they are young will help keep individuals healthier as they age.

This novel helped show me that even hard working individuals may not always thrive in their old age and we must rethink our policies as they stand now. Caring for sick individuals will almost always cost more than caring for healthy individuals. Allowing them to be able to care for themselves by working and paying into a system setup to assist everyone, without the worry of status, would benefit America and its citizens as a whole.

\subsection{Discussion of Reflections}

Student reflections reveal a myriad of issues that came to light as a result of the work related to reading and working with the novel. Topics reflected a deeper understanding of theories and issues including the life course 
perspective, economics, socioeconomic status, health care and related policies. The framework that tied this all together, the story of Kate Quinton and her experiences helped to ground the reflections and insights in the context of immigration and later life.

5. Discussion of fitting within AGHE Gerontological Competencies

In 2014, the Academy for Gerontology in Higher Education (AGHE) approved the first set of gerontological competencies. These competencies are meant to serve as a guide to educators working with gerontology students and act as a framework for the development of skills, knowledge, and abilities as students go through their programs. The use of the AGHE competencies was an important part of the development of the curriculum for this particular class and the specific project. Below are the competencies that were integrated into the framework and as a way for students to further understand the objectives and expectations and for the instructor to assess the knowledge gained in the context of outcomes. The AGHE competencies were used as the course objectives and to assess student learning outcomes.

\section{AGHE Competencies/Course Objectives}

- Competency 1.1.1: Employ the Lifespan/Lifecourse perspectives to appreciate age over time in relation to the life transitions \& adaptive resources.

- Students exhibited a deeper understanding of the lifecourse perspective as reflected in their writing, discussions, and final presentations.

- Competency 1.1.4: Interpret the gerontological frameworks in relationship to aspects \& problems of aging persons, their families, their environment \& communities.

- Through the use of the novel, students revealed an ability to connect the various relationships in the framework of gerontology which provided a pathway to knowledge.

- Using their knowledge of theoretical constructs in aging, students discussed these connections vis-a-vis Kate and her experiences.

- Competency 1.6.5: Use critical thinking to evaluate information \& its source (popular media \& research publications).

- Bringing in outside material, current affairs such as newspaper articles, and current scholarly journal articles, students were able to connect the novel to current day practices and experiences.

- Competency 11:1: Develop a gerontological perspective through knowledge \& self-reflection

- Through reflective journaling and discussions students were able to share their insight and knowledge gained.

- Competency 11.3.2: Listen \& actively engage in problem solving to develop research, programs, and policies with key stakeholders.

- Through class discussions and group activity engagement students learned to apply their acquired knowledge through the lens of problem solving.

As Niles-Yokum \& Wagner (2019) remind us, "As the field of gerontology grows and the population of older adults continues to increase, the need for a gerontologically educated workforce becomes a critical factor in our ability to provide a good old age for everyone in our society (p.202)." This includes thinking outside the box in our attempts to educate our students. Using novels, and other tools creates a space for learning that brings us all together in unexpected ways.

Additionally, de Mederiros (2017) argues that we must consider the complexities of policies in the context of aging. The complexities of immigration policies and the challenges of older immigrants must be a focus as we move into our 21 st quarter century. Our Hispanic population is set to increase to over $20 \%$ in 2025 , and we are moving to a minority majority by 2045 . Thus our students will be working with vastly different backgrounds than previous generations. The aging immigrant population will include all races, ethnicities, and religious groups, which will also call for a shift in our reliance on "how things used to work." Our care systems and structures will need to change to keep up with the changing demographics, As Brown, Niles-Yokum, and Baker (2020) state, "individuals should not have to figure out how to navigate communities that no longer work for 
them. Instead, as gerontologists, it is our responsibility to build a better world where we can all live better lives" (p. 114).

\section{References}

$\mathrm{ABC}$ of women workers' rights and gender equality. Geneva, International Labour Office, 2007

http:/www.ilo.org/wcmsp5/groups/public/---dgreports/---gender/documents/publication/wcms_087314.pdf

Association for Gerontology in Higher Education. (2014). Gerontology Competencies.

Blackie, M., \& Wear, D. (2015). Three things to do with stories: Using literature in medical, health professions, and interprofessional education. Academic Medicine: Journal of the Association of American Medical Colleges, 90, 1309-1313.

Brown, P., \& Niles-Yokum, K. (2016). Kate's journey: Introducing students to the human side of aging services and supports. Gerontology \& Geriatrics Education, 37, 232-254.

Brown, P., Niles-Yokum, K., \& Baker, H. (2020). Social Theories of Aging: A Brief Synopsis. San Diego, CA: Cognella Publishing.

Burke, K. (1989). Literature as Equipment for Living. In D. H. Richter (Ed), The Critical Tradition: Classic Texts and Contemporary Trends, (pp. 512-517). New York: St. Martin's Press.

Coles, R. (1989). The call of stories: Teaching and the moral imagination. Boston, MA: Houghton Mifflin.

Deering, C. G. (2017). Using Literature to Teach Crisis Intervention. Psychology Learning \& Teaching. DOI: $10.1177 / 1475725717723837$

deMedeiros, K. (2017). The short guide to aging and gerontology. Bristol, UK: Policy Press.

DeVault, M.L. (1991). Feeding the family: The social organization of caring as gendered work. Chicago: University of Chicago Press.

DMani, S. (2011). Interdisciplinary learning: An innovative use of a literature module in medical education. The English Teacher, 40, 60-68.

Donohoe, M. (2013). Using literature to teach medical students about public health and social justice. In M. Donohoe (Ed.), Public health and social justice (pp. 597-608). San Francisco, CA: Jossey-Bass.

Duffy, M.C. (2011) "Making care count: a century of gender, race, and paid care work", Making care count: a century of gender, race, and paid care work

Duffy, M. (2005). Reproducing Labor Inequalities Challenges for Feminists: Conceptualizing Care at the Intersections of Gender, Race, \& Class. Gender \& Society, 19(1), pp. 66-82.

Flood, D., \& Farkas, C. A. (2011). Teaching madness and literature in a healthcare context: An enquiry into interdisciplinary education. Mental Health Review Journal, 16, 128-137.

Folbre, N. (2012). For Love \& Money: Care Provision in the United States. New York, NY: Russell Sage Foundation.

Folbre, N., \& Wright, E. O. (2012). "Defining Care,” Pp. 20-39 in Nancy Folbre's (Ed), For Love \& Money: Care Provision in the United States. New York, NY: Russell Sage Foundation.

Freeman, L. H., \& Bays, C. (2007). Using literature and the arts to teach nursing. International Journal of Nursing Scholarship, 4, 1-14.

Gelman, C. R., \& Mirabito, D. M. (2005). Practicing what we teach: Using case studies from 9/11 to teach crisis intervention from a generalist perspective. Journal of Social Work Education, 41, 479-494.

Gordon, J. J., \& Evans, H. M. (2007). Learning medicine from the humanities. Edinburgh, UK: Association for the Study of Medical Education.

Hamaji, K., \& González-Rivera, C. (2016). A City of Immigrant Workers: Building a Workforce Strategy to Support All New Yorkers. Center for an Urban Future. https://nycfuture.org/research/a-city-ofimmigrant-workers-building-a-workforce-strategy-to-support-all-ne

Hartmann, H., Hayes, J., Huber, R., Rolfes-Haase, K., \& Suh, J. (2018). The Shifting Supply and Demand of Care Work: The Growing Role of People of Color and Immigrants. Institute for Women's Policy 
Research. \#C470, June 2018. Washington, DC: IWPR. Retrieved from: https://iwpr.org/wpcontent/uploads/2018/06/C470_Shifting-Supply-of-Care-Work-Immigrants-and-POC.pdf

Jarrott, S.E., \& McCann, B. R. (2013). Analysis of intergenerational relationships in adolescent fiction using a contact theory framework. Gerontology \& Geriatrics Education, 34, 292-308. doi: $10.1080 / 02701960.2012 .737387$

Miller, M. (2017). Aging United States must get the economics right on immigration. Reuters. Retrieved from: https://www.reuters.com/article/us-column-miller-immigration/aging-united-states-must-get-theeconomics-right-on-immigration-idUSKCN1BP184

Niles-Yokum, K. \& Wagner, D.L. (2015). The Aging Networks: A Guide to Programs and Services. 8th edition. Springer Publishing, New York, NY.

Niles-Yokum, K. \& Wagner, D. L. (2019). The Aging Networks: A Guide to Policy, Programs, and Services, 9th Edition. New York, NY: Springer Publishing.

Rolen, E. (2017). The Growing Need for Eldercare Workers. U.S. Department of Labor Blog. Retrieved from: https://blog.dol.gov/2017/05/08/the-growing-need-for-eldercare-workers

Romero, M. (1992). Maid in the U.S.A. New York: Routledge.

Scourfield, J., \& Taylor, A. (2014). Using a book group to facilitate student learning about social work. Social Work Education, 33, 533-538.

Sheehan, S. (1984). Kate Quinton's Days. Boston: Houghton Mifflin.

Sheets, D. J. (2013). Editor's Introduction. Symposium: Popular Literature on Aging. The Gerontologist, 53 (6), 1060-1070. 